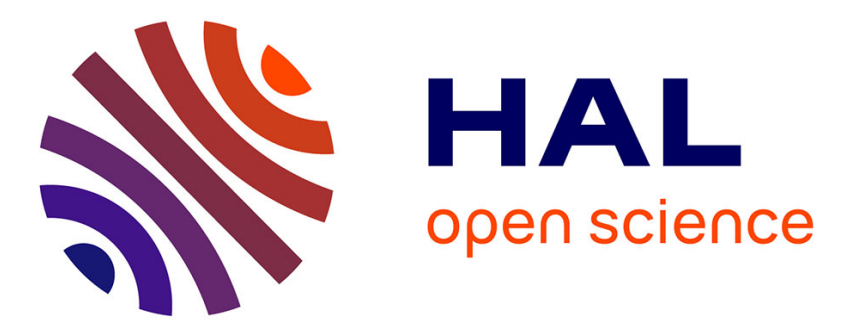

\title{
Humanities 2.0: documents, interpretation and intersubjectivity in the digital age
}

Aurélien Bénel, Christophe Lejeune

\section{To cite this version:}

Aurélien Bénel, Christophe Lejeune. Humanities 2.0: documents, interpretation and intersubjectivity in the digital age. International Journal of Web Based Communities, 2009, 5 (4), pp.562. 10.1504/IJWBC.2009.028090 . hal-02918419

HAL Id: hal-02918419

https://hal-utt.archives-ouvertes.fr/hal-02918419

Submitted on 29 Dec 2021

HAL is a multi-disciplinary open access archive for the deposit and dissemination of scientific research documents, whether they are published or not. The documents may come from teaching and research institutions in France or abroad, or from public or private research centers.
L'archive ouverte pluridisciplinaire HAL, est destinée au dépôt et à la diffusion de documents scientifiques de niveau recherche, publiés ou non, émanant des établissements d'enseignement et de recherche français ou étrangers, des laboratoires publics ou privés. 


\title{
Humanities 2.0: document, interpretation and intersubjectivity in the digital age*
}

\author{
Aurélien Bénel** and Christophe Lejeune*** \\ ** Tech-CICO, Charles Delaunay Institute, University of Troyes, \\ 12, rue Marie Curie, BP 2060, 10010 Troyes, France \\ E-mail: aurelien.benel@utt.fr \\ *** Department of Information and Communication Sciences, \\ Faculty of Philosophy and Humanities, University of Brussels, \\ 50/123, F. D. Roosevelt Av. \\ 1050 Brussels, Belgium \\ E-mail: christophe.lejeune@ulb.ac.be
}

\begin{abstract}
With their focus on documents, interpretation and intersubjectivity, Web 2.0 technologies have surprising analogies with philosophical hermeneutics, the theory of texts interpretation.

Philosophical hermeneutics was generalised from biblical hermeneutics by Dilthey in the 19th century, and chosen as an alternative to positivism as a foundation for the epistemology and methodology of the humanities and social sciences.
\end{abstract}

This article explores how Web 2.0 technologies might better meet the needs of social and human sciences than traditional information technologies that are historically bound with logical positivism. Illustrations are provided from archaeology and sociology, two social and human sciences which were early adopters of punched cards and computers.

\section{Keywords}

Web 2.0, Collaborative methods, Digital humanities, Hermeneutics, Intersubjectivity, Epistemology.

\footnotetext{
* The authors are thankful to Alex Fenton for his comments about a preliminary version of this article.
} 


\section{Biographical notes}

Aurélien Bénel is an associate professor in computer science in an interdisciplinary CSCW laboratory (ICD/Tech-CICO, Troyes). In his PhD on "semantic" access to documents in archaeology, he introduced the idea of a collaborative hypermedia solution, where traces of human interpretation are collected, shared and can be used to structure corpora. His main interests are on the computer-human interactions and visualization tools needed by "digital hermeneutics": annotation, interpretation trails, viewpoints confrontation... Some of these ideas are implemented and tested in the Porphyry software. He is also involved in the specification of Hypertopic, a computer protocol to manage multi-viewpoint knowledge models.

Christophe Lejeune is a researcher in communication sciences at the University of Brussels. In his $\mathrm{PhD}$ (in sociology), he conducted participant observation of the Open Directory Project, a collective voluntary effort at indexing website addresses, considered a precursor of the Web 2.0. Latterly, he has studied the regulation of discussion flora, web communities and involvement in free software. His research is currently focussed on trust in mediated communities and mutual help in such collectives. From a methodological point of view, he is interested in the use of software in qualitative analysis. In particular, he developed the Cassandre software for textual analysis that is mentioned in this paper. 


\section{Introduction}

The title of this article, "Humanities 2.0", is not an attempt to create a new buzzword, but to prompt thinking about the links that could exist between "Web 2.0", the new participatory trend on the Web, and the social and human sciences.

The link is not straightforward when looking at the most used "tags" on web 2.0 sites such as "wedding", "travel" and "friends" on Flickr, "hot", "rock", and "dance" on Dailymotion, or "webdesign", "software" and "web2.0" on Del.icio.us. Even when used for culture and science as in Wikipedia, participatory technologies are often criticised by researchers (Lacour, 2008).

However, when designing Digital Humanities applications, there is a choice between two major trends on the Web: "Web 2.0" and the "Semantic Web". Our claim is that Web 2.0 is more suited to the humanities and social sciences, because its technologies have analogies with philosophical hermeneutics, the theory of interpretation inspired by biblical hermeneutics, and proposed by Dilthey (19th century) as the epistemology and methodology for humanities and the social sciences.

We will focus on documents, interpretation and intersubjectivity. For each of these dimensions, we first investigate how Web 2.0 technologies differ from traditional information technology. We then reflect on how they are related to hermeneutics. Subsequently we illustrate how they could be of use in archaeology and sociology, two social and human sciences which were early adopters of punched cards and computers.

\section{Document-driven inquiries}

\section{Web 2.0 \& documents}

Whereas computers were first created to compute numbers, and whereas corporate information technology was mainly intended to manage and share data, "Web 2.0" applications are designed to let users share their own digital documents, for example: videos (YouTube, Dailymotion), photographs (Flickr), slides (Slideshare) and texts (blogs, wikis).

Nevertheless, sharing digital documents instead of "data" or "facts" is not really new. For example, in 1993, one of the first French websites was the Universal Bibliophiles' Association (ABU), in which public-domain texts were uploaded by voluntary transcribers (Cubaud \& Girard, 1998). Several similar projects even existed prior to the Web: ArXiv, an open-access repository for "preprints" in physics, was created in 1991 using a mailing list and an FTP server; Project Gutenberg was started in 1971 to share literary and historical texts in the public domain via a mainframe on one of the few nodes of what would later become the Internet.

Given the recent widespread adoption of document self-publishing technologies, a few projects presage what they would bring to digital humanities. One of the best examples is NietzscheSource (formerly HyperNietzsche), which offers not only online facsimiles of primary sources such as manuscripts, page proofs and letters, but also secondary material as transcriptions, translations, "genetic paths" (revision layers)... (D'Iorio, 2007).

\section{Hermeneutics \& documents}

For Dilthey, documents are the basis of the scientific study of human and society. At the end of the 19th century, as a reaction to Comte's positivism, he stated that such studies were possible, despite the singularity of the human subjects, because those subjects' live were fixed in structured "sets" (e.g. texts) that can be understood by others (Ricœur, 1986, p.92-93). He adopted as his 
epistemology a philosophical hermeneutics generalised from biblical hermeneutics (the theory and method of the Bible interpretation).

That the Bible is the exemplar of the hermeneutic text can be seen in the name "Old (or New) Testament". In Latin, "testamentum" means that something has been attested or testified. It is a "proof" of something else, not in the manner of a mathematical proof but more in that of a juridical one: a testimony to be kept, a document to be brought as evidence. Indeed, the Gospels were written by witnesses because Jesus, as Socrates, was an orator, not a writer (Ricœur, 1986, p.138-140). Moreover, those texts are a first interpretative layer, a first confession of faith of the early Christian community (Ricœur, 1969, p.378), just as the whole Bible ties together narrations and confessions of faith (Ricœur, 1986, p.134-137). Therefore, the Scriptures, which tell of people who interpret signs, have themselves to be interpreted as signs.

In a philosophical hermeneutics also, contrary to a referential semantics, meaning is mediated by texts. It is worth noting that "testimonia" has a similar etymology to "testamentum" and is used in philology and history for manuscripts and stone inscriptions. There has been lately a renewal of interest in these questions because, after decades of success of models of social structures and strongly generalised theories, social researchers now stress the importance of empirically grounded interpretation whilst recognising that human and social phenomena cannot be directly addressed. To gain a material status, to be preserved and to be used as proofs, phenomena are "translated" (Callon, 1986) into a series of documents.

\section{Illustration in archaeology}

To speak of the centrality of documents in archaeology may be controversial since the discipline differentiates itself from history by its study of artefacts rather than texts. Museums and collections are full of physical artefacts, but we must consider the particular status of scientific archives in archaeology. For example, at the French school of archaeology in Athens, every map and photograph produced in the course of funded initiatives must be stored in the institutional archive, even if access to the document may be restricted. Although most of these intermediary documents remain unpublished, there is a requirement to keep evidence through space and time. In fact, the actual artefacts and sites are often distant or difficult to access, and need nevertheless to be shown to peers or studied in libraries or laboratories. Moreover, ancient artefacts are frequently destroyed or at least altered, not only by natural processes, vandals or real estate developers, but also by the very act of excavation which destroys their context. For these reasons it is important that the context is carefully recorded in documents. In a sense, the only way to bring reproducibility to an archaeological dig is in fact to virtually "dig" these documents which were produced about it (Iacovella et al., 2005).

Intermediate documents cannot be considered "data" for several reasons. Firstly, measurements, maps and even photographs are the results of selective perception, which springs from the concerns, hypotheses and methods of their author. Therefore they have to be "documented" with situational clues (often called "metadata") so that the reader can situate them in their original history. Secondly, archaeological artefacts have sometimes been studied over several centuries. In such cases, their inventory identifiers have often changed through time, whereas visual documents can still be identified with them. In a way, these documents appear to be the only perennial references. Thirdly, some researchers think that there are no epistemological differences in archaeology between what are usually called "primary sources" (ancient texts), "secondary sources" (commentaries) and "data" produced in the present. If we assume that artefacts do not have inherent attributes, but only through documents (ancient or modern), all of these documents can be considered "sources" (Desfarges \& Helly, 1991).

In recent years, we have developed and experimented with prototype software on various kinds of 
archaeological sources, including series and monographs from a research centre, annual excavation chronicles from a particular country, 19th century reports from the excavation of a necropolis, and photographs of vases from a particular city depicting a particular subject. Figure 1 shows how a photograph from a scientific archive might be documented in our software platform ${ }^{1}$.

Figure 1: Documented photograph from a scientific archive showing an inscribed block

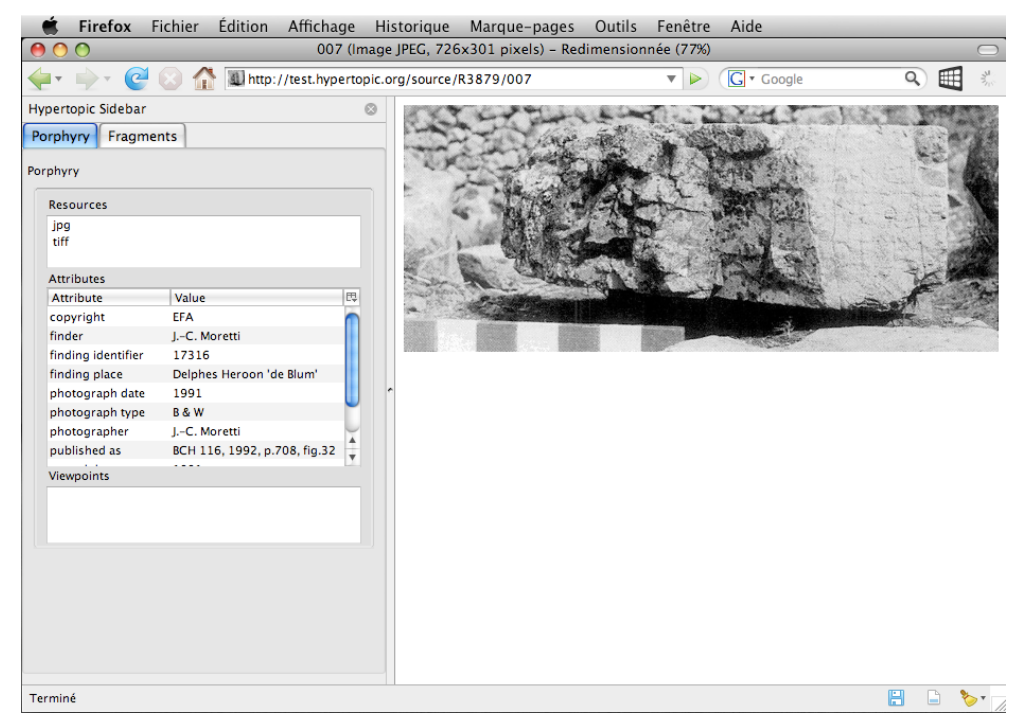

\section{Illustration in sociology}

One might be tempted to argue that sociology is concerned with phenomena (such as representation, belief or experience), not with documents. However, such social phenomena cannot be addressed without recording (as audio, or video, for example) of interaction and everyday life in natural settings, or by the social scientist's interviewing of selected actors. Thus, the nature of sociological documents may vary. For instance, in exploratory research on civil society, Gautier Pirotte gathered a corpus composed of annual reports and public statements of non-governmental organisations, and press articles about them (Pirotte, 2007). Traditionally, social scientists not only collect documents, but participate in their production: Sébastien Brunet, Pierre Delvenne and Catherine Fallon carried out several group interviews with neighbourhood committees about electromagnetic risks (mainly related to mobile phones); the transcribed discussions (see Figure 2) are combined with the text of legislation to comprise the research corpus (Brunet et al., 2008).

Figure 2: Frequent, repeated and specific tokens from a focus group on electromagnetic risks

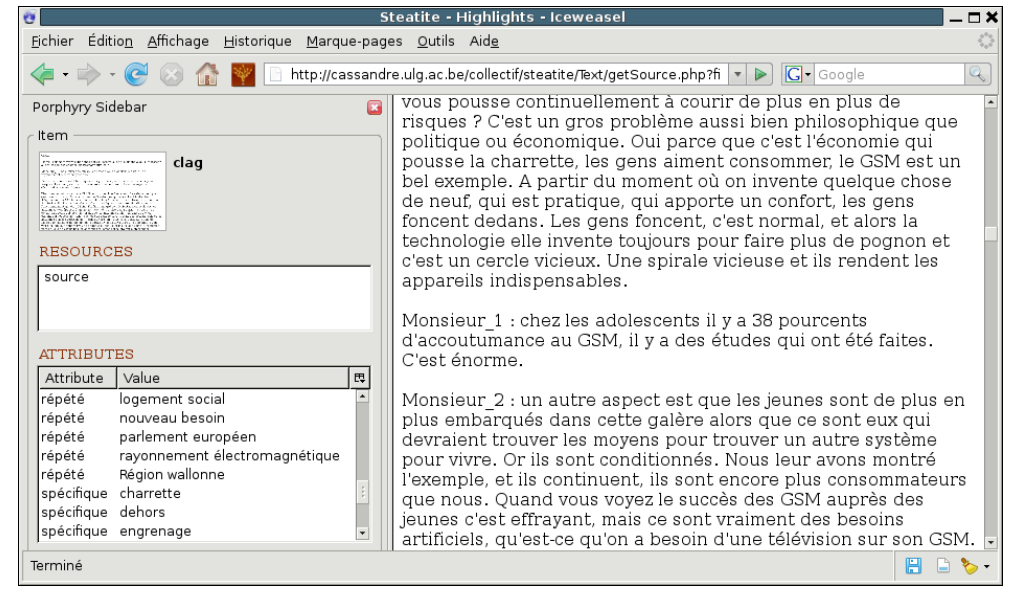

\footnotetext{
${ }^{1}$ Porphyry, Cassandre and Argos are available as open-source software.
} 
In each study, the researchers assembled a corpus in order to test research hypotheses. The leading criterion is thus the relevance of the documents to the research topic, not the documents' format. Social phenomena are thus not directly recorded as data, they are "translated" into intermediate documents. This translation is the subject of a classic debate: given that the conduct of a biographical interview or field observation varies according to the assumptions, hypotheses and theoretical orientation of the researcher, only precise (though reasonable) methodological principles can warrant this intermediate document as an accurate surrogate for the social phenomenon being investigated (Bourdieu, 1998).

\section{Interpretation}

\section{Web 2.0 \& interpretation}

Computer science has a very close relationship with artificial intelligence, especially through the figure of Alan Turing, a parent common to both. The "Turing machine" (1936) prefigured the computer by being the first abstract programmable device which was proved to be capable of computing whatever is computable, whilst the "Turing test" (1950) was one of the first attempts to define "machine intelligence". It might then be thought quite surprising to find that the Web has evolved into a "Web 2.0", where every user can contribute to content, "harnessing collective intelligence" (O'Reilly, 2005), rather than into a "Semantic Web" with "content that is meaningful to computers" (Berners-Lee et al., 2001)2.

In fact, by implementing "folksonomic tagging" (Del.icio.us, Flickr, Connotea...) and "trackbacks" (blogs), Web 2.0 site designers have chosen human interpretation rather than automatic deduction. Both of these features can be seen as "hypertext" features as envisioned in 1965 by its inventor, Theodor Nelson. Indeed, as a philosophy and sociology graduate, he wanted to provide "literary machines" to cope with "text issues". And, one of the main features was "transclusion", letting the reader quote and virtually combine existing documents into new documents (Nelson, 1999). By tagging shared resources, Web 2.0 users accomplish similar combining and aggregating operations.

\section{Hermeneutics \& interpretation}

One of the major concepts of hermeneutics is represented by the phrase "liber et speculum", which means both that "the mystery contained in the text is made explicit in our experience" and that "we understand ourselves in the mirror of the words" (Ricœur, 1969, p.377). In that sense, it concerns every great text of humanity from the Odyssey to the Qur'an, because of their renewed currency. However, Paul Ricœur wondered why the hermeneutic method was first created explicitly for the Bible, and in particular for the Christian Bible (Ricœur, 1969, p.373-380). First, the canon intentionally kept four gospels and also four creation stories (Gen.1, Gen.2, Es.40-55, Jn.1) with consequent contradictions from a strictly logical perspective. Secondly, some passages say that others have to be read "allegorically" (e.g. Paul in his letter to the Galatians says that Abraham's wives descent can be read as an allegory of two alliances). Lastly, the "New Testament" constantly refers to and interprets the "Old Testament". To conclude, the awareness of the hermeneutic problem in the Bible can be explained by the inner plurality of the text. Furthermore, Paul Ricœur notes that any attempt to avoid this plurality has been declared heretic (e.g. Marcionism in the 2nd century, which rejected the Old Testament and kept only one Gospel).

\footnotetext{
${ }^{2}$ The Semantic Web advocates automatic deductions based on the description of resources with formal and standardized vocabularies (named "ontologies"). Imposing no such formal constraints on resources descriptors, Web 2.0 proposes an alternate strategy.
} 
In philosophical hermeneutics, the idea of "liber et speculum" is called "understanding" by Dilthey. For him, this subjective interpretation would have the same role for human sciences as that of "explanation" for natural sciences. However, the explanation, which strength is taken as a function of the number of convergent clues aligned by the scientist (Latour, 1988), can also be seen as a complementary mode for the interpretation needed in human sciences (Ricœur, 1986).

As stated by Weber (1978), questions of subjectivity are misleading, or misunderstood. For years, social scientists have seen subjectivity as something risky, something that must be avoided, hidden or destroyed. Rather, the researcher must be aware of her position in the social world and of the (implicit or explicit) commitments of her methodological and epistemological framework. These determine the researcher's subjectivity. If not taken into account, this subjectivity can yield unexpected results (by filtering materials, for instance). In this regard, subjectivity is seen as an obstacle. This is why Pierre Bourdieu, quoting Gaston Bachelard, warns social scientists against their own implicit common-sense assumptions (Bourdieu et al., 1991).

The subjectivity in this context is that of the researcher; that of actors is not of concern (Lejeune, 2001) In fact, the actor's common sense (subjectivity) is a fruitful source for social inquiry: it constitutes the material of the social sciences. Without the common sense of actors, no social inquiry would be possible. Moreover, understanding requires empathy of the researcher. In other words, the researcher should be able to share the actor's cultural background (Schütz, 1967). Common humanity makes this possible: the researcher uses his own ordinary actor's subjectivity as a tool to fully understand the life-world of other actors. The researcher's subjectivity is thus also a resource (as a tool) to access the actor's subjectivity (as the receptacle of the social phenomenon being investigated).

Finally, the researchers' subjectivity is made up of selected assumptions, questions and theoretical commitments. This observation can be taken as an objection to the conception of subjectivity as an impediment. That is what Max Weber, considered as the founder of comprehensive social science, does when he argues that being an anarchist is not an obstacle for a Professor of Law, but rather offers a fresh perspective likely to rejuvenate legal theory (Weber, 1949). Subjectivity thus renders one's interpretation rich and, as we will show, is a condition for scientific debate.

As we noted above, understanding recovers a cultural background and awareness of one's historical involvement (Gadamer's Wirkungsgeschichtliches Bewusstsein). Thus understanding demands consideration of the historical context of the phenomenon, the context of the analysis, and the difference between these two subjectivities. Because of this alterity, subjectivity does not imply a lack of scientific rigour; it is a warrant of it.

\section{Illustration in archaeology}

The interpretative status of archaeology was greatly debated in the sixties and seventies among proponents of a "new archaeology" and defenders of a "humanistic archaeology". A nice illustration of this debate is provided by Anne-Marie Guimier-Sorbets' thesis on the analysis and formalisation of geometric ornaments in Graeco-Roman mosaics for automatic processing. Philippe Bruneau, who was on her examining board, wrote a subsequent article which spawned an unprecedented polemic.

Discussing the status of "descriptors" in the so-called "archaeological databanks", he argued, first, that descriptors such as "foreground" or "background" are usually chosen in order to be universal, independent of era and geography; and that that itself should be quite surprising in a historical science.

Secondly, he asked, what is the validity of "foreground" and "background" in a case like Greek 
frets, where every black fret on white has a complementary white fret on black? Anne-Marie Guimier-Sorbets answered: "by convention, the fret to be analysed is the outer one of the mosaic. The other complementary part is analysed as background". Philippe Bruneau noted that it was a shame to decide "by convention" that the whole description would be from the border to the centre whereas mosaics were built from the central panel to the border.

Lastly, the very term "descriptor", connoting agency, would lead one to think that it is not the archaeologist but the device that describes an artefact. And to forget the archaeologist as the describer leads one to forget that the first to describe and classify the artefact was indeed the ancient user himself (Bruneau, 1976).

It is worth noting that recent work by archaeologists such as Roland Etienne adopts an historiographical perspective. In historiography (the history of history), there is not a single historical meaning, but rather a succession of actualised meanings. Moreover, history is seen as the result of confrontation between past and present, between that which organised life and thought in those days and that which makes it possible to think about them in the present(de Certeau, 1975).

Our prototype software allows the researcher to build freely her own analytic framework, depending on her hypotheses, and to revise it accordingly. For example, Figure 3 shows the qualitative analysis developed by masters-level students in history of $\operatorname{art}^{3}$ of the scenes depicted on photographs of vases.

Figure 3: Qualitative analysis of the scenes depicted on vases

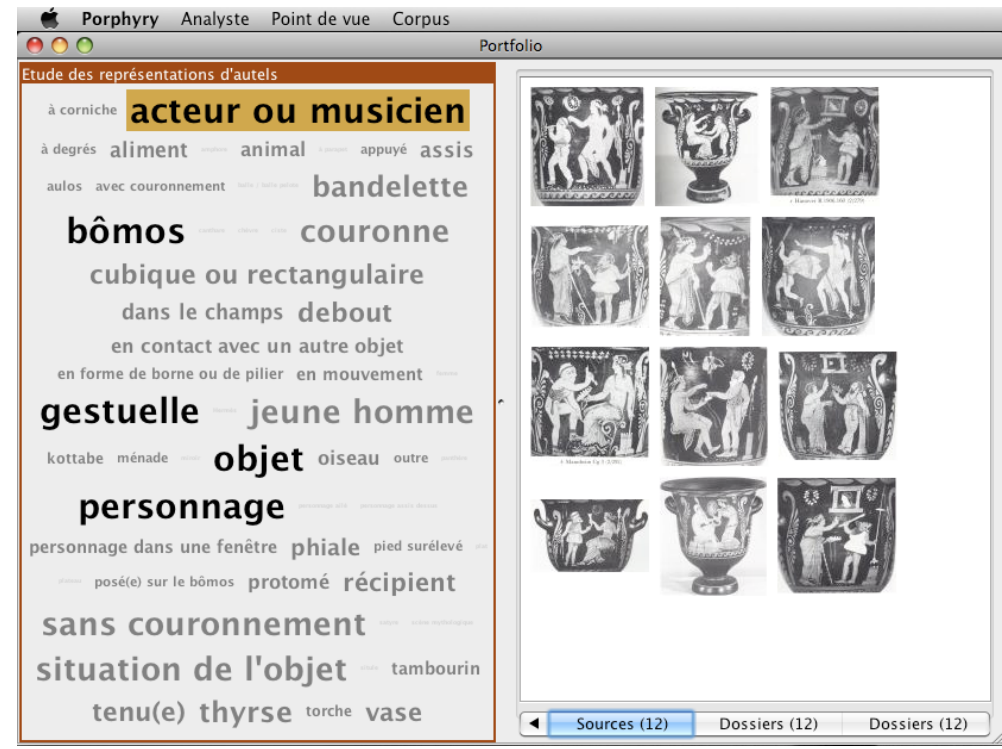

\section{Illustration in sociology}

As we discussed above, interpretation raises issues of subjectivity. Let us illustrate this with the previously mentioned sociological example of electromagnetic risk. Even in sociological enquiries so driven by textual documents, a temptation remains to discount the researcher's subjectivity, it being seen as an obstacle. Analytical techniques such as quantitative content analysis (Berelson, 1952) seek to achieve such an exclusion. Teams of content analysts are provided with the textual material and a set of possible annotations. They are asked to literally code the material using these standard annotations. Only annotations that reach a high level of agreement (calculated as inter-

\footnotetext{
${ }^{3}$ Marion Lagarde, Elodie Lacrampe and Clélia Robinet, under the direction of Jean-Marc Luce and Pascale Jacquet (CRATA Laboratory, University of Toulouse II, France).
} 
coder reliability) are retained (Krippendorff, 2004). The subjectivity of a sole researcher is thus overcome ${ }^{4}$.

More frequently, the researcher's subjectivity is manifested as an epistemological position toward the actor's subjectivity. The researcher might assume that actors are irrational with regard to risk. Occurring before (and independently of) examination of intermediate documents in which actors precisely express their points of view, this prejudice is part of the researcher's subjectivity. It acts as a filter, and is thus an obstacle to interpretation.

As an alternate position, more and more social scientists assume that intermediate documents are evidence of actor's subjectivity (consisting of beliefs or conceptions, for example, about electricity pylons). As an illustration of subjectivity-as-paradigmatic-commitment, the researcher could then assume that actors reason about their interests; she thus traces the development of natural theories of counter-intuitive effects and "self-fed phenomena" (see Figure 4 and Lejeune, 2008 for details). Notice that this position - consistent with the parallel programme of the anthropology of science and technology (Latour, 1988) - takes the opposite view to a presumption of an actor's irrationality.

Figure 4: Analysis of "self-fed phenomena" in electromagnetic risk perception

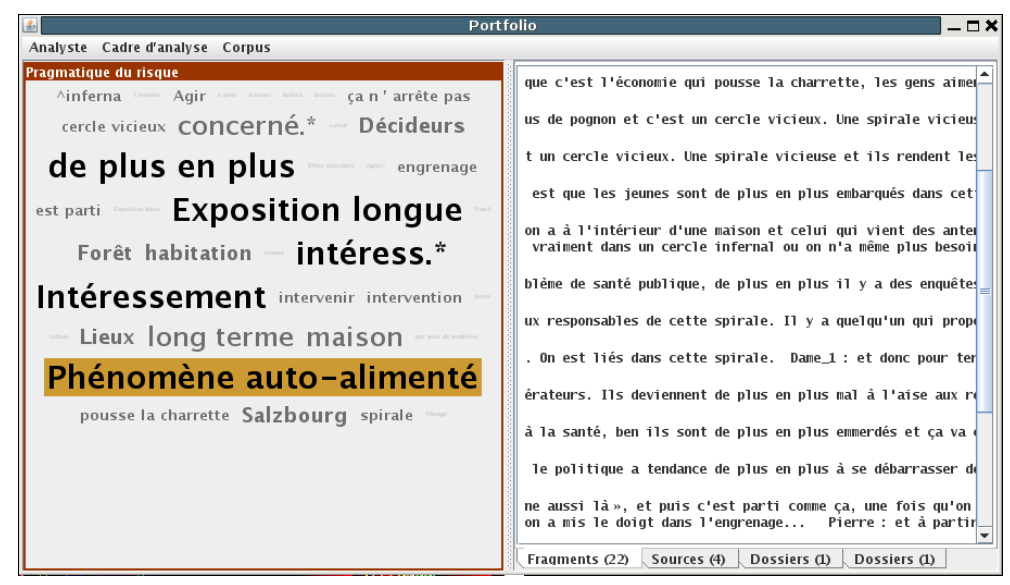

Moreover, in sociology, there are as many possible interpretations as there are paradigms. The issue of subjectivity is addressed differently according to the paradigm chosen. For instance, when Bourdieu studied artistic activity, he focussed on social positions, and on strategies aimed at preserving those positions. In his brilliant analysis of jazz musicians, Becker adopts a different perspective - exhibiting how interactions take place locally, under local rules (Becker, 1963). In each case, researchers are taking care not to project their subjectivity onto the documents they collect, but their interpretations nonetheless differ in the paradigm from which they originate. Whatever the field, a number of analyses can be (and are) carried out, producing concurrent interpretations. Even within a given paradigm, selected researchers do not interpret the documents the same way. This contributes to the richness of the interpretative work in scientific work.

\section{Intersubjectivity}

\section{Web 2.0 \& intersubjectivity}

Since the advent of time-sharing mainframe computers, information technology has allowed thousands of users to work together on a digital medium. However, the novelty of Web 2.0 is the

4 Such a quantitative content analysis assesses an epistemological framework similar to the Semantic Web's positivist assumptions. 
massive usage of multi-user systems of loosely organised volunteers. Whereas traditional information technologies focus on consensual (or imposed) data structures (database schemas, ontologies) and work processes (workflows, business processes), Web 2.0 technologies bring the dissensus among users to the fore by showing the thread of reader comments on a blog post, the "cloud" of tags assigned by different readers to documents, or the "discussion" tab on a wiki page.

The intersubjective technologies of Web 2.0 can be seen as scaled-up versions of earlier technologies prototyped in digital libraries, such as shared comments and "landmarks" for collaborative filtering (Röscheisen et al., 1995) or scholars' "viewpoints" to improve indexing (Bénel et al., 1999, Nanard \& Nanard, 2001).

\section{Hermeneutics \& intersubjectivity}

The theory of the multiple meanings of texts ("multiplex intellectus") is also a crucial point of biblical hermeneutics (Ricœur, p.376-377). Origen of Alexandria (3rd century) and later Christian exegetes distinguished:

- a "literal" meaning, to be learnt (because the words were written by other people of another time),

- an "allegorical" meaning, to be believed (because the words can be seen as signs from another time for today),

- a "moral" meaning, to act in accordance with ("moral" means "related to manners"),

- an "anagogical" or "mystical" meaning, to tend to ("anagogical" means "raising", and "mystical" means "kept silent").

Those meanings are also present in the Jewish tradition as "Pshat", "Remez", "Drash" and "Sod". In a mystical tale by Moshe Cordovero (16th century), each of these meanings (abbreviated to "P", "R", "D", "S") is a level of the same "PaRDeS" (garden). It is worth noting that in this tale, every meaning is explored by a different rabbi.

In philosophical hermeneutics, the alterity between the social world and the analyst is completed with a second alterity between her viewpoint and that of her colleagues. After subjectivity, intersubjectivity becomes a test of the analysis. Indeed, as stated by sociologists of science, confrontation between conflicting viewpoints is core to the dynamics of the scientific field (Bourdieu, 1976; Merton, 1979). However, a critical challenge remains in broadening intersubjectivity beyond paradigms, methods, and disciplinary borders.

\section{An archaeological illustration}

Even the early promoters of "archaeological "databanks" wondered about the possible effect of differences between experts' viewpoints. Jean-Claude Gardin, although he advocated a "logicist program" in humanities, had to admit that it was impossible to think about archaeological databases without wondering about the acceptance of these data by the whole archaeological community (Gardin, 1984). René Ginouvès and Anne-Marie Guimier-Sorbets went further by advising database designers to incorporate intersubjectivity, rather than hoping to achieve a hypothetical consensus which would certify the objectivity of the data (Ginouvès \& Guimier-Sorbets, 1978). However, no practical solution was given on how to implement such intersubjective databases.

One of the most important features of our prototype software prototype is enabling the comparison of different analytical frameworks as different viewpoints on the same corpus of documents. Figure 
5 illustrates this by showing two analyses, executed by different students, of photographs of geometric vases.

Figure 5: Comparison of two analyses of the same geometric vases

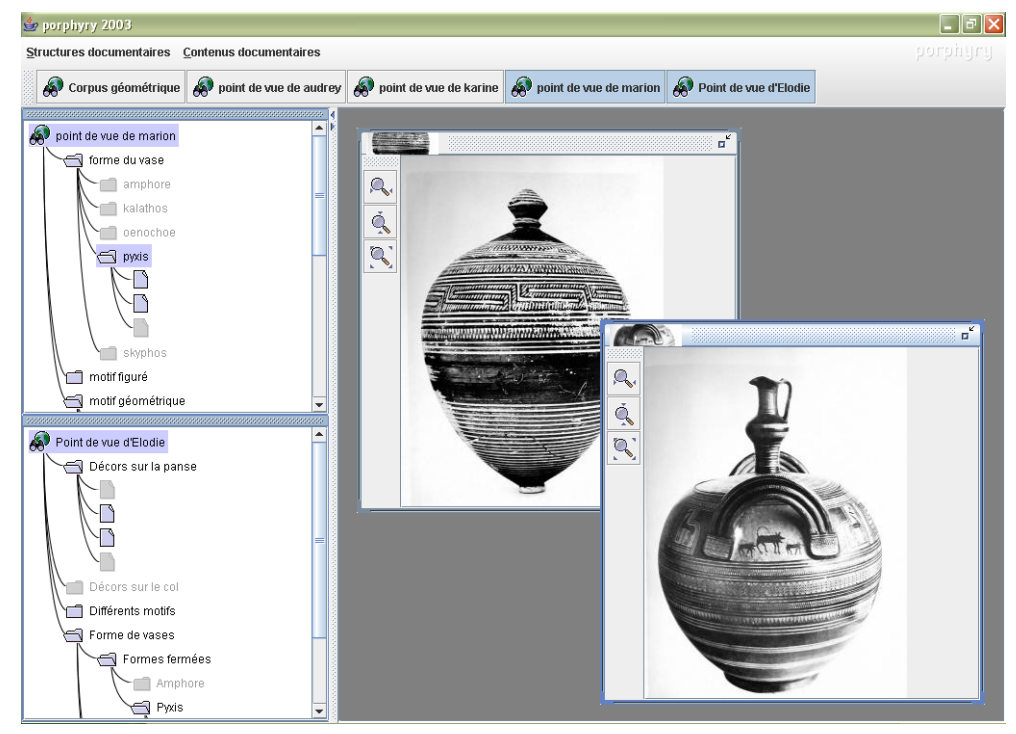

Recent archaeological projects attest that complex artefacts are studied from different disciplines, and result in bibliographies which rarely intersect. For example, Bruno Helly noted that gravestones and funerary monuments are independently studied with reference to their sculpture, paintings, architecture, inscriptions, and also the origin and cut of the stone. He stated that using a digital medium to contrast disciplinary viewpoints would be an apt way to understand such a complex object as a whole (Iacovella et al., 2005).

\section{A sociological illustration}

Numerous sociologists address the same phenomenon, but they rarely share their material (Rigot, 2006). Moreover, given that sociology is divided into paradigms and schools, scientific debates occur only inside each paradigm. The fact that sociologists belonging to different paradigms study similar phenomena does not necessarily generate debate, given that "you adhere to a paradigm, you do not demonstrate its validity." (Rigaux, 1992, p.21).

However, debate is not absent. In the eighties, the anthropology of science happened to restate the social constructionist paradigm. The social constructivists, for whom science results from social interaction, challenged the realistic view that scientific facts reflect the world out there. The debate resulted in a refined social constructivism. According to this (new) perspective, the power of scientific discovery results from multiple contributions. As a consequence, facts are powerful because they are constructed, not despite that. The controversy, and thus, the conflict between schools of social scientists contributed to a richer perspective (Simmel, 1964).

Similar controversies can occur within our software platform. As with the anthropology of science, these debates contribute to the formulation of more powerful interpretations. For instance, the sociologist Gautier Pirotte used our tools in order to study French versions of international NGO annual reports that mention the notion of civil society (see Figure 6). He compared two concurrent theories: the "economy of worth" (Boltanski \& Thevenot, 2006) and his own theory of civil society (Pirotte, 2007). Another example came from within the same paradigm: in research on the perception of electromagnetic risk, members of a team in political science developed two concurrent viewpoints, on the basis of the same documents, in this case transcribed focus groups (Brunet et al., 2008). 
Figure 6: Alternate analyses of NGO reports in terms of economy of worth and civil society

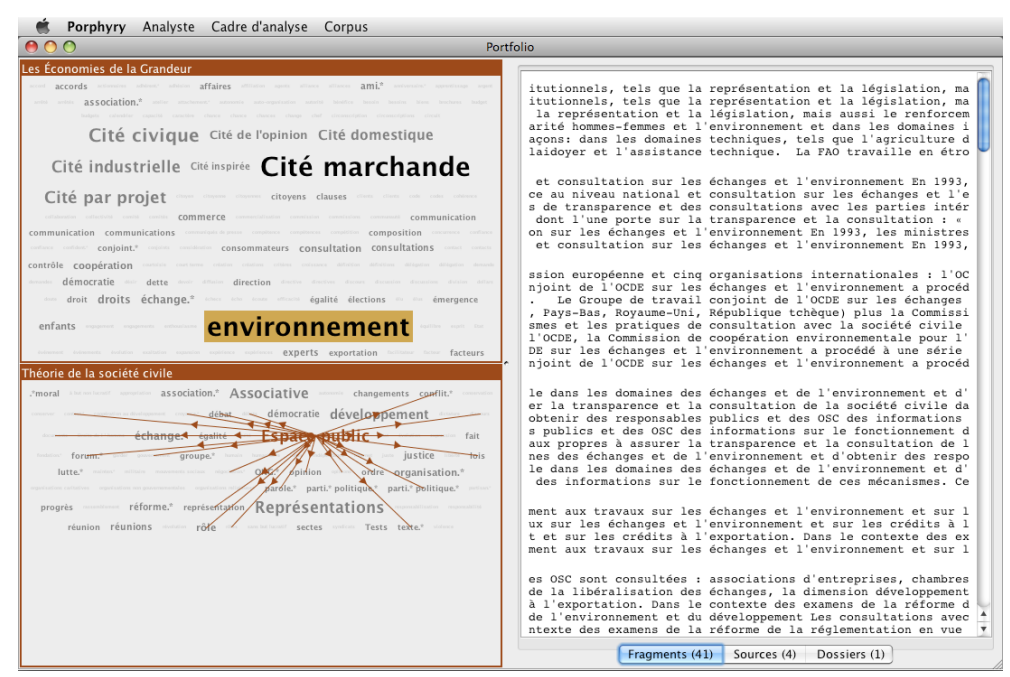

\section{Conclusion}

In this paper we explored how Web 2.0 technologies could be considered as a resurgence of hermeneutics, while traditional information technology can be seen as the offspring of logical positivism. We illustrated how philosophical hermeneutics intersects the main methodological debates within archaeology and sociology. For these disciplines, we saw how software can be designed and prototyped on notions such as document-driven enquiry, interpretation and intersubjectivity, in order to provide a convenient medium for researchers to carry out their analyses. We hope that the success and maturity of Web 2.0 will foster digital humanities, and humanities themselves, in an unprecedented way.

\section{References}

Howard Becker, 1963, Outsiders. Studies in the Sociology of Deviance, Free Press.

Aurélien Bénel, Sylvie Calabretto \& Jean-Marie Pinon, 1999, ‘Indexation "sémantique" de documents archéologiques', in Deuxième colloque du chapitre français de l'ISKO, Lyon, 21-22 Octobre 1999. Available on: http://benel.tech-cico.fr/publi/benel_ISKO_99.pdf

Bernard Berelson, 1952, Content Analysis in Communication Research, Glencoe: The Free Press.

Tim Berners-Lee, James Hendler \& Ora Lassila, 2001, 'The Semantic Web', in Scientific American, May 2001. Available on: http://www.sciam.com/article.cfm?id=the-semantic-web

Luc Boltanski \& Laurent Thevenot, 2006, On Justification: Economies of Worth, Princeton University Press.

Pierre Bourdieu, 1976, 'Le champ scientifique', Actes de la recherche en sciences sociales, vol. 2, $\mathrm{n}^{\circ} 2$, pp.88-104.

Pierre Bourdieu, 1992, The Logic of Practice, Stanford University Press.

Pierre Bourdieu, 1998, Practical Reason: On the Theory of Action, Stanford University Press.

Pierre Bourdieu, Jean-Claude Chamboredon \& Jean-Claude Passeron, 1991, Craft of Sociology: Epistemological Preliminaries, de Gruyter.

Philippe Bruneau, 1976, 'Quatre propos sur l'archéologie nouvelle', in Bulletin de Correspondance Hellénique, $\mathrm{n}^{\circ} 100$, tome 1, p.103-135. Available on:

http://www.persee.fr/web/revues/home/prescript/article/bch_0007-4217_1976_num_100_1_2035 
Sébastien Brunet, Pierre Delvenne, Catherine Fallon et Christophe Lejeune, 2008, 'La perception du risque en situation de haute incertitude scientifique : le cas des champs électromagnétiques en Belgique', Politique et sociétés, soumis pour publication.

Michel Callon, 1986, 'Some Elements of a Sociology of Translation: Domestication of the Scallops and the Fishermen of St Brieuc Bay', pp.196-233 in John Law (Ed.), Power, Action and Belief: A New Sociology of Knowledge, London: Routledge \& Kegan Paul.

Pierre Cubaud \& Didier Girard, 1998, 'ABU : une bibliothèque numérique et son public', Documents numériques, vol. 2, Hermès. Available on: http://jasmin.cnam.fr:8081/RR9813/

Patrick Desfarges \& Bruno Helly, 1991, 'L'archéologie, système d'information scientifique' in Aplicaciones Informaticás en Arqueologia : Teorias y sistemas. Saint-Germain-en-Laye.

François Dosse, 1998, Empire of Meaning: The Humanization of the Social Sciences, University of Minnesota Press.

Jean-Claude Gardin, 1984, 'Les bases de données dans les sciences de l'antiquité : l'ajustement nécessaire des fins aux moyens', in Banques de données et sciences de l'antiquité.

René Ginouvès \& Anne-Marie Guimier-Sorbets, 1978, La constitution des données en archéologie classique. Ed. du CNRS.

Klaus Krippendorff, 2004, Content Analysis: An Introduction to Its Methodology, Thousand Oaks: Sage.

Andrea Iacovella, Aurélien Bénel, Sylvie Calabretto \& Bruno Helly, 2005, 'Assistance à l'interprétation dans les bibliothèques numériques pour les sciences historiques', in Actes du colloque de bilan du programme interdisciplinaire "Société de l'information" 2001-2005, p.167179. Available on: http://publi.tech-cico.fr/paper_details.php?paperid=41

Paolo D'Iorio, 2007, 'Nietzsche on New Paths: The HyperNietzsche Project and Open Scholarship on the Web', in Maria Cristina Fornari, Sergio Franzese (éds.), Friedrich Nietzsche. Edizioni e interpretazioni, Pisa ETS. Available on: http://www.hypernietzsche.org/doc/files/new-paths.pdf Philippe Lacour, 2008, 'Portrait de l'intellectuel en DJ : Wikipédia face à l'expertise scientifique', in La vie des idées. Available on: http://www.laviedesidees.fr/Portrait-de-l-intellectuel-en-DJ.html

Bruno Latour, 1988, Science in Action: How to Follow Scientists and Engineers Through Society, Harvard University Press.

Christophe Lejeune, 2001, 'Du mode de définition de deux programmes de recherche en sociologie et en ethnométhodologie', Carnets de Bord, Volume 2, pp.56-66. Available on: http://www.carnetsde-bord.ch/revue/article.php?NoArt=9\&num $=2$

Christophe Lejeune, 2008, 'Au fil de l'interprétation. L'apport des registres aux logiciels d'analyse qualitative', Swiss Journal of Sociology, Volume 34, Issue 3, pp.593-603.

Robert King Merton, 1979, The Sociology of Science, Southern Illinois University Press.

Marc Nanard \& Jocelyne Nanard, 2001, 'Cumulating and sharing end users knowledge to improve video indexing in a video digital library', in Proceedings of the first ACM/IEEE-CS Joint

Conference on Digital Libraries (JCDL'01), ACM Press. p.282-289. Available on: http://doi.acm.org/10.1145/379437.379683

Theodor Holm Nelson, 1999, 'Xanalogical Structure Needed Now More Than Ever', in $A C M$ Computing Surveys, Volume 31, Issue 4, ACM Press. Available on:

http://www.cs.brown.edu/memex/ACM_HypertextTestbed/papers/60.html

Tim O'Reilly, 2005, 'What is Web 2.0: Design Patterns and Business Models for the Next

Generation of Software', September 30, 2005. Available on:

http://www.oreillynet.com/pub/a/oreilly/tim/news/2005/09/30/what-is-web-20.html 
Gautier Pirotte, 2007, La notion de société civile, Paris: La découverte.

Natalie Rigaux, 1992, Raison et déraison. Discours médical et démence sénile. Bruxelles: De Boeck.

Huguette Rigot, 2006, '(En)-jeux de corpus pour la recherche en SHS. Enoncés, textes et documents', in François Ratier \& Michel Ballabriga (dir.), Corpus en Lettres et Sciences sociales : des documents numériques à l'interprétation, Actes du colloque international d'Albi, Paris: Texto.

Paul Ricœur, 1969, Le conflit des interprétations : Essais d'herméneutique, Paris: Seuil.

Paul Ricœur, 1986, Du texte à l'action : Essais d'herméneutique II, Paris: Seuil.

Martin Röscheisen, Christian Mogensen \& Terry Winograd, 1995, 'Beyond browsing: Shared comments, soaps, trails, and on-line communities', in The Third International World Wide Web Conference, "Technology, Tools and Applications". Available on:

http://www.igd.fhg.de/archive/1995_www95/proceedings/papers/88/TR/WWW95.html

Alfred Schütz, 1967, Phenomenology of the Social World, Northwestern University Press.

Georg Simmel, 1964, Conflict And The Web Of Group Affiliations, Free Press.

Max Weber, 1978, Economy and Society: An Outline of Interpretive Sociology, University of California Press.

Max Weber, 1949, Methodology of the social sciences, Free Press.

Manuel Zacklad, Aurélien Bénel, Jean-Pierre Cahier, L'Hédi Zaher, Christophe Lejeune \& Chao Zhou, 2007, 'Hypertopic : une métasémiotique et un protocole pour le Web socio-sémantique' in Francky Trichet (dir.), Actes des 18eme journées francophones d'ingénierie des connaissances, pp.217-228, Cépaduès (France). Available on: http://publi.techcico.fr/paper_details.php?paperid=79 